\title{
Empirical Research on the Factors Affecting Core Competence Evolution of Logistics Enterprises Based on Service Innovation
}

\author{
Bo Yang ${ }^{1, a}$ and Jiaqi Lu $^{1, b}$ \\ ${ }^{1}$ School of Information Management,Jiangxi University of Finance and Economics, Nan Chang \\ 330013, China \\ ayb_Ih@163.com, blujiaqi20@163.com
}

Keywords: Service Innovation, Evolution of Core Competence, Principal Component Analysis

\begin{abstract}
This paper puts forward a conceptual model of influencing factors of logistics enterprises core competence evolution process based on the theories of service innovation and presents 12 key influencing factors after analyzing the previous research achievements. After analyzing the date by factor analysis method with software SPSS19.0, the results show that, from the perspective of service innovation,the 12 key factors can be classified as six factors which are innovation factor, resource factor,cultural factor, competitive factor,environmental factor and marketing management factor.
\end{abstract}

\section{Introduction}

Under the trend of economic globalization, the logistics industry has become an emerging industry with huge development potential.Although China's logistics industry is developing rapidly, there are still many problems.For example, service level of logistics industry ascending slowly and the core competitive ability of logistics enterprise is generally not high.Under such circumstances, it is necessary to improve the core competitiveness of logistics enterprises by improving service innovation.It can improve the relationship between enterprises and users and improve the efficiency of enterprise's logistics operation.With the service innovation is more and more important to the logistics enterprise, service innovation ability has gradually become one of the most important core competence of logistics enterprises.

Domestic and foreign experts study the impact factors of the logistics enterprises core competence mainly from the static and qualitative angle [4,5]. But there are little study from the point of view of the core competence dynamic evolution of logistics enterprises and combined with the evolution process of logistics enterprise service innovation ability.So in this paper, study the impact of the core competence of logistics enterprises from service innovation view using quantitative analysis method have a certain academic value.

\section{The influence factors model of logistics enterprises core competence evolution based on service innovation}

Scholars at home and abroad have done a lot of research on the core competence of logistics enterprises from various angles. Haire believed that the evolution process of a firm core competence is similar to the growth curve of the organism,from birth, growth, maturity to decay and death and there are cycles[1].Logistics enterprises core competence evolution experienced three stages, respectively is logistics enterprises core competence formation stage, the core ability increase stage, the core ability ascension phase[2].The evolution of the logistics enterprises core competence is the evolution result of various capabilities[3].Weiping $\mathrm{Yu}$ (2003) found that human resources, marketing ability, innovation ability, management ability, enterprise culture, strategic management ability, production capacity and industry environment influence the core competence of logistics enterprise in different extent[6]. Guohua Zhou (2012) thinks that influencing factors of logistics enterprise are internal and external influencing factors from the perspective of enterprise boundary and build a "subject-object-environment " influencing factors model from the perspective of dynamic logistics service innovation[5].Xi Wang(2013) found that the external environment, technical ability, 
innovation strategy and organizational structure affect the core competence of the enterprise[4].Yeyong Yang (2014) found that the service level of logistics enterprises, technical ability, ability to integrate resources and human resources and so on influence the core competence of logistics enterprise [7].

Based on the domestic and foreign literature, this paper puts forward the concept model of logistics enterprise core competence evolution based on service innovation. The conceptual model is shown in Figure 1.The main influencing factors are internal and external.The 12 factors are the acquisition of external knowledge,human resources, technological innovation, the ability to implement the program, the shaping of corporate culture, the ability to expand the market, decision-making capacity, service flow optimization, strategic planning ability.

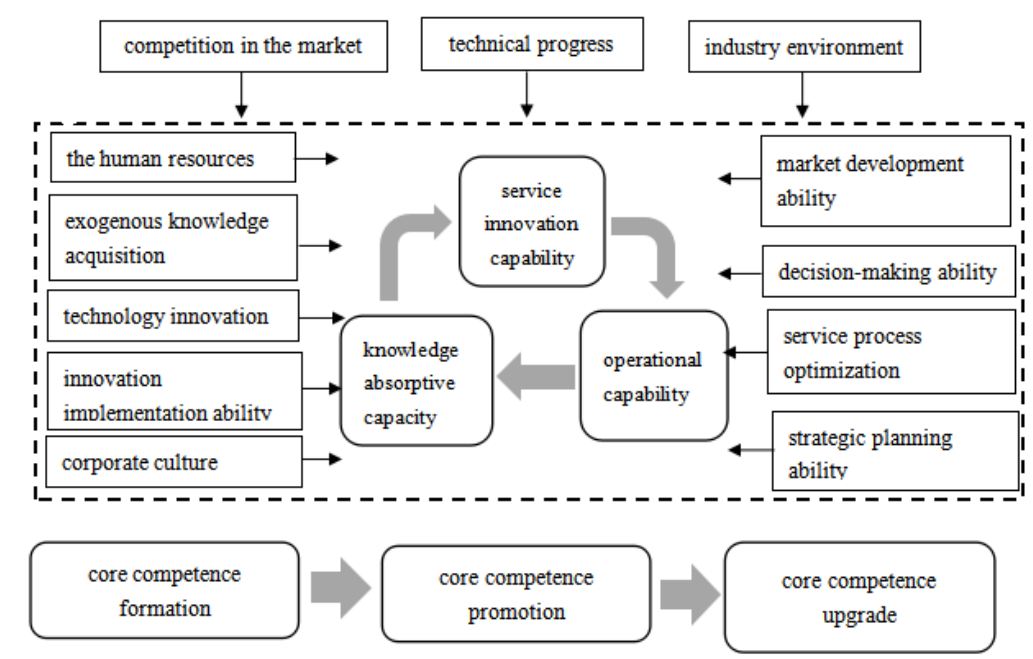

Fig. 1 Logistics enterprise core competence evolution influencing factors conceptual model

\section{The questionnaire design}

In this paper, we use empirical methods to verify the impact factor model.The empirical methods consist of field interview and questionnaire survey.Questionnaire design directly determine the reliability and validity of the statistical analysis results. We firstly draw up draft questionnaire through the literature retrieval,then we carry on the preliminary investigation and study, analysis and investigate on the completeness of the questionnaire and the understanding of the problem, and revise and supplement the questionnaire according to the feedback.This paper puts forward 12 kinds of factors which influence logistics enterprise core competence evolution. They mainly refer to the existing literature ( Sundbo J, Galloujf(1998),D.Little(2007)and Yu Weiping(2003)etc' questionnaire design for related problems. The questionnaire consists of two parts. The first part is about the survey of the general situation of logistics enterprises and the service innovation behavior. The second part is the main part of logistics enterprise core competence evolution model based on service innovation.Before carrying on the factor analysis, we first need to evaluate and score the influence degree of influence factors. Based on the evaluation data, we conduct a comprehensive analysis, comparison and induction by using principal component analysis method.The evaluation data of the influencing factors is obtained on the basis of the investigation of the special population.Through the analysis of the main influencing factors, this paper summarizes the main factors that affect the technological innovation of enterprises as 12 factors. Details are shown in table 1.

These main factors together constitute the main body of the questionnaire, and the main purpose of the questionnaire is to understand professional people's cognitive situation of factors affecting the logistics enterprise core competence.The questionnaire was designed according to the 12 factors in Table 1. Likert five evaluation method was used in the questionnaire.In the five questionnaires, the influence factors were evaluated according to their importance.The value of the score indicates the importance of each variable.It is divided into 5 grades, from 1 to 5 the degree of influence gradually 
strengthened,respectively as"minimal impact,less impact,general impact,greater impact,considerable impact”.

Table 1.main variables of logistics enterprise core competence evolution based on service innovation

\begin{tabular}{|c|c|c|}
\hline variable & influence factor & variable interpretation \\
\hline H1 & technical progress & $\begin{array}{l}\text { the impact of technical progress on the evolution of } \\
\text { logistics enterprise core competence }\end{array}$ \\
\hline $\mathrm{H} 2$ & technology innovation & $\begin{array}{l}\text { the impact of technology innovation on the evolution of } \\
\text { logistics enterprise core competence }\end{array}$ \\
\hline H3 & $\begin{array}{l}\text { corporate culture shaping } \\
\text { force }\end{array}$ & $\begin{array}{l}\text { the impact of corporate culture shaping force on the } \\
\text { evolution of logistics enterprise core competence }\end{array}$ \\
\hline $\mathrm{H} 4$ & $\begin{array}{c}\text { innovation } \\
\text { implementation ability }\end{array}$ & $\begin{array}{l}\text { the impact of innovation implementation ability on the } \\
\text { evolution of logistics enterprise core competence }\end{array}$ \\
\hline H5 & $\begin{array}{l}\text { service process } \\
\text { optimization }\end{array}$ & $\begin{array}{l}\text { the impact of service process optimization on the } \\
\text { evolution of logistics enterprise core competence }\end{array}$ \\
\hline H6 & industry environment & $\begin{array}{l}\text { the impact of industry environment on the evolution of } \\
\text { logistics enterprise core competence }\end{array}$ \\
\hline H7 & $\begin{array}{l}\text { market development } \\
\text { ability }\end{array}$ & $\begin{array}{l}\text { the impact of market development ability on the evolution } \\
\text { of logistics enterprise core competence }\end{array}$ \\
\hline H8 & $\begin{array}{l}\text { exogenous knowledge } \\
\text { acquisition }\end{array}$ & $\begin{array}{l}\text { the impact of the ability to acquire external knowledge } \\
\text { resources on the evolution of logistics enterprise core } \\
\text { competence }\end{array}$ \\
\hline H9 & human resources & $\begin{array}{l}\text { the impact of human resources on the evolution of } \\
\text { logistics enterprise core competence }\end{array}$ \\
\hline H10 & decision-making ability & $\begin{array}{l}\text { the impact of decision-making ability on the evolution of } \\
\text { logistics enterprise core competence }\end{array}$ \\
\hline H11 & competition in the market & $\begin{array}{c}\text { the impact of competition in the market on the evolution } \\
\text { of logistics enterprise core competence }\end{array}$ \\
\hline H12 & strategic planning ability & $\begin{array}{l}\text { the impact of strategic planning ability on the evolution of } \\
\text { logistics enterprise core competence }\end{array}$ \\
\hline
\end{tabular}

\section{The survey statistics and analysis}

The questionnaire mainly focuses on logistics enterprises which pay attention to service innovation. The scope of the investigation includes large logistics enterprises in Beijing, Shanghai, Guangzhou and Jiangxi.The investigation object includes the logistics enterprise management personnel, technical personnel and the first line staff of logistics enterprise.Survey method is on-site interviews combined with e-mail exchanges. We take the spot interview in Beijing and Jiangxi and take the form of e-mail investigation in other areas.To make ensure the objectivity and comprehensiveness of the questionnaire survey, the sampling scope mainly includes logistics enterprises of Beijing, Shanghai,Guangzhou and other economically developed areas, including Small and medium sized logistics enterprises in Nanchang high tech Development Zone.A total of 150 questionnaires were issued and 98 questionnaires were recovered, the recovery rate was 65\%.

\section{Data processing and statistical tests}

Reliability test.Reliability shows the correctness and accuracy of the measurement tools.Cronbach's alpha reliability coefficient is used as the main index in this paper.The overall Cronbach's Alpha coefficient is 0.853 and the half Cronbach's Alpha coefficient is 0.827.It can be considered that the questionnaire design of this study is of high reliability and good internal consistency.Test results are shown in Table 2. 
Table 2 The half and total reliability analysis of logistics enterprise core competence evolution factors based on service innovation

\begin{tabular}{c|c}
\hline Part1 & 0.765 \\
\hline Part2 & 0.764 \\
\hline Guttman Split-Half Coefficient & 0.827 \\
\hline Cronbach's Alpha & 0.853 \\
\hline
\end{tabular}

Validity test. In this study, the KMO and Bartlett test is used to verify the suitability of the questionnaire.KMO and Bartlett ball test results are shown in table 3.The empirical results of KMO in the table is 0.747 , indicating that there is little difference between the variables.Bartlett sphere chi-square test approximation in the table is 595.600, which shows factor analysis is suitable.To sum up, it is suitable for using factor analysis in this research.

Table 3 The KMO and Bartlett ball test results of logistics enterprise core competence evolution factors based on service innovation

\begin{tabular}{|c|c|c|}
\hline \multicolumn{3}{|c|}{ KMO and Bartlett's Test } \\
\hline Kaiser-Meyer-Olkiı & ampling Adequacy. & 0.747 \\
\hline \multirow{4}{*}{$\begin{array}{l}\text { Bartlett's Test of } \\
\text { Sphericity }\end{array}$} & Approx. & 595.60 \\
\hline & Chi-Square & 6 \\
\hline & Df & 66 \\
\hline & Sig. & .000 \\
\hline
\end{tabular}

\section{The main factor analysis of main influencing factors}

The factor load matrix after rotation is shown in table 4.

Table 4 factor load matrix after rotation

\begin{tabular}{|c|c|c|c|c|c|c|}
\hline & \multicolumn{6}{|c|}{ Component } \\
\hline & 1 & 2 & 3 & 4 & 5 & 6 \\
\hline 1.technical progress & .060 & -.088 & -.137 & -.051 & .927 & .039 \\
\hline 2.technology innovation & .953 & .002 & .037 & -.077 & -.034 & .041 \\
\hline $\begin{array}{l}\text { 3.corporate culture shaping } \\
\text { force } \\
\end{array}$ & .107 & -.182 & .935 & -.064 & -.109 & -.005 \\
\hline $\begin{array}{l}\text { 4.innovation implementation } \\
\text { ability } \\
\end{array}$ & .890 & .012 & .136 & -.214 & .139 & -.050 \\
\hline $\begin{array}{c}\text { 5.service process } \\
\text { optimization }\end{array}$ & .069 & -.232 & .113 & .121 & -.056 & .9 .31 \\
\hline 6.industry environment & .030 & .101 & -.016 & -.064 & .943 & .037 \\
\hline 7.market development ability & .175 & -.327 & -.020 & .089 & -.020 & .836 \\
\hline $\begin{array}{c}\text { 8.exogenous knowledge } \\
\text { acquisition }\end{array}$ & -.042 & .920 & -.282 & .136 & .008 & -.192 \\
\hline 9.the human resources & .107 & .764 & -.308 & -.195 & .017 & -.425 \\
\hline 10.decision-making ability & .006 & -.290 & .064 & .109 & .166 & .897 \\
\hline 11.competition in the market & -.278 & .014 & .051 & .935 & -.110 & -.037 \\
\hline 12.strategic planning ability & -.145 & .043 & .099 & -.254 & -.029 & .873 \\
\hline
\end{tabular}

Extraction Method: Principal Component Analysis.

Rotation Method: Varimax with Kaiser Normalizati.

a.Rotation converged in 3 iterations.

In table 4,the first factor includes technology innovation and innovation implementation ability,known as innovation factor.The second factor includes exogenous knowledge acquisition and human resources,known as resource factor. The third factor is corporate culture shaping force,known as cultural factor.The fourth factor is competition in the market,known as competitive factor. The fifth factor includes technical progress and industry environment,known as environmental factor.The sixth 
factor is service process optimization,market development ability,decision-making ability and strategic planning ability,known as marketing management factor.

\section{Conclusion}

Through the empirical study, we can find that external factors and internal factors have a impact on logistics enterprises core competence evolution process.First,innovation implementation ability is the guarantee of logistics enterprise service innovation capability.Second, resources integration of logistics has a great influence on promoting enterprise's core competence.Third, Marketing development ability help logistics enterprises expand the market.Decision-making ability guides logistics enterprise to make right decisions. Strategic planning ability mainly help logistics enterprise make future planning from strategic view. Service process optimization mainly improve service quality of logistics enterprise.Fourth,enterprise culture affects the operating efficiency of logistics enterprises.In terms of external influence factors, including environmental factors and competitive factors, market changes or environmental turbulence affects logistics enterprise service innovation ability and technology affects the logistics enterprise technology track updates.

\section{Acknowledgements}

This work was financially supported by the National Natural Science Foundation project (71640022), Science and technology research project of jiangxi province Ministry of education(no:14322). Humanities and social science research project of jiangxi province colleges and universities(No:gl1423) the Jiangxi Province Social Science "Twelfth Five Year Plan" project( 15TQ04) and 2016 university research innovation projects of special funds .

\section{References}

[1] Haire M:Biological Models and Empirical History of the Growth of Organization: Modern Organizational Theory(John Wiley and Sons Publications,New York 1959).

[2] Lin He and Huiping Ding:submitted to Journal of Business management(2009),In Chinese.

[3] Xue Tian:submitted to Journal of Logistics technology(2014),In Chinese.

[4] Xi Wang:Study on the evaluation of modern logistics enterprise service innovation performance based on entropy-topsis( Jilin University Publications,Jilin 2013).

[5] Guohua Zhou:Research on the factors influencing service innovation of logistics enterprises(Huazhong University of Science and Technology Publications, Wuhan 2012 ).

[6] Weiping Xu:submitted to Journal of Social sciences front(2003),In Chinese.

[7] Yeyong Yang:submitted to Journal of Logistics technology(2014),In Chinese. 